\title{
PENGETAHUAN REMAJA PUTRI MENGENAI ANEMIA DEFISIENSI BESI DAN PENCEGAHANNYA DI KECAMATAN JATINANGOR
}

\author{
Puspa Sari $^{1}$, Tina Dewi Judistiani², Widi Pertiwi ${ }^{3}$, Merry Wijaya ${ }^{4}$, \\ Sefita Aryuti Nirmala ${ }^{5}$, dan Astuti Dyah Bestari ${ }^{6}$ \\ 1,2,3,4,5,6 Program Studi DIV Kebidanan, Fakultas Kedokteran, Universitas Padjadjaran \\ 1,2,4,5,6 Departemen Ilmu Kesehatan Masyarakat, Fakultas Kedokteran, Universitas Padjadjaran \\ 1,2,5 Pusat Studi Immunologi, Fakultas Kedokteran, Universitas Padjadjaran \\ E-mail: puspa.sari@unpad.ac.id
}

\begin{abstract}
ABSTRAK. Anemia defisiensi besi pada remaja putri masih menjadi masalah di Indonesia, termasuk di Kecamatan Jatinangor Kabupaten Sumedang. Berdasarkan penelitian yang dilakukan oleh peneliti pada tahun 2016 pada remaja putri di SMA Kecamatan Jatinangor, terdapat $45,2 \%$ remaja putri yang mengalami anemia defisiensi besi. Risiko dari anemia defisiensi besi pada jangka panjang yaitu ibu hamil dengan anemia, hal ini berdampak pada kesehatan bayi yang dilahirkan dari ibu tersebut. Beberapa faktor yang menjadi penyebab dari anemia defisiensi besi pada remaja putri, salah satunya adalah pengetahuan mengenai anemia dan pencegahannya masih kurang. Metode penelitian dan pengabdian masyarakat yang dilakukan adalah potong lintang, dengan jumlah sampel 69 remaja SMA di Kecamatan Jatinangor. Berdasarkan hasil survey melalui kuesioner, pengetahuan remaja mengenai anemia dan pencegahannya hanya 2 orang yang memiliki pengetahuan baik. Setelah diperolah hasil penelitian, dilakukan pengabdian masyarakat dengan memberikan pendidikan kesehatan mengenai anemia dan pencegahannya. Kesimpulan dari kegiatan pengabdian pada masyarakat ini adalah perlu dilakukan pendidikan kesehatan berkelanjutan guna meningkatkan pengetahuan remaja putri mengenai anemia dan pencegahannya.
\end{abstract}

Kata kunci: anemia; pengabdian masyarakat; pengetahuan; pendidikan kesehatan

ABSTRACT. Iron deficiency anemia in adolescent girls is still a problem in Indonesia, including in Jatinangor District, Sumedang. Based on research conducted by researchers in 2016 in adolescent girls in Hight School Jatinangor, there were 45.2\% of adolescent girls who had iron deficiency anemia. The risk of iron deficiency anemia in the long term is if they pregnant they will be get anemia, this has an impact on the health of babies born and to mothers. Some factors that cause iron deficiency anemia in adolescent girls is lack of knowledge about anemia and prevention. The research method was cross-sectional, with a sample of 69 high school adolescent girls in Jatinangor District. Based on the results of the survey through a questionnaire, the knowledge of adolescents about anemia and its prevention is only 2 people who have good knowledge. After obtaining the results of research, community service is carried out by providing health education about anemia and its prevention. The conclusion of community service activities is that it is necessary to carry out continuing health education in order to increase the knowledge of young women about anemia and its prevention.

Key words: anemia; community service; health education; knowledge

\section{PENDAHULUAN}

Anemia merupakan salah satu masalah nutrisi yang banyak terjadi di negara berkembang maupun maju. World Health Organization (WHO) memperkirakan jumlah orang yang menderita anemia di seluruh dunia sekitar dua miliar, dimana 50\% anemia disebabkan defisiensi zat besi. Faktor risiko utama anemia defisiensi besi adalah asupan dan penyerapan zat besi yang buruk serta periode kehidupan ketika kebutuhan akan zat besi sangat tinggi, seperti pada masa pertumbuhan dan kehamilan. Diantara penyebab anemia lainnya, adalah kehilangan darah akibat menstruasi, atau infeksi parasit seperti cacing tambang, ascaris, dan schistosomiasis, infeksi akut dan kronis, termasuk malaria, kanker, tuberkulosis, dan HIV yang dapat menurunkan konsentrasi hemoglobin darah ( $\mathrm{Hb})$.

Menurut Survei Kesehatan Rumah Tangga (SKRT) tahun 2012 prevalensi anemia pada balita sebesar 40,5\%, ibu hamil sebesar 50,5\%, ibu nifas sebesar $45,1 \%$, remaja putri usia 10-18 tahun sebesar 57,1\% dan usia $19-45$ tahun sebesar $39,5 \%$. Remaja putri mempunyai risiko terkena anemia paling tinggi terutama pada masa remaja. Menurut hasil penelitian yang dilakukan oleh WHO di negara berkembang, prevalensi anemia pada remaja putri usia subur yang tidak hamil (usia 15-49 tahun) mencapai $41,5 \%$. Indonesia merupakan salah satu negara berkembang dengan prevalensi anemia pada remaja putri sebesar 37\% lebih tinggi dari prevalensi anemia di dunia. Menurut Departemen Kesehatan pada tahun 2012, Jawa barat memiliki angka kejadian anemia pada remaja putri sebesar $51,7 \%$.

Anemia dapat menimbulkan risiko pada remaja putri baik jangka panjang maupun dalam jangka pendek. Dalam jangka pendek anemia dapat menimbulkan keterlambatan pertumbuhan fisik, dan maturitas seksual tertunda. Dampak jangka panjang remaja putri yang mengalami anemia adalah sebagai calon ibu yang nantinya hamil, maka remaja putri tidak akan mampu memenuhi zat-zat gizi bagi dirinya dan juga janin dalam kandungannya yang dapat menyebabkan komplikasi pada kehamilan dan persalinan, risiko kematian maternal, angka prematuritas, BBLR dan angka kematian perinatal.

Peran pendidikan kesehatan mengenai defisiensi besi serta pengetahuan nutrisi sangat penting. Terdapat dua cara pencegahan yaitu primer dan sekunder. Pencegahan primer yaitu melalui pendidikan kesehatan agar remaja mendapat masukan besi melalui makanan yang mencukupi kebutuhannya. Pencegahan sekunder terdiri dari skrining, 
diagnosis, dan pengobatan defisiensi besi. Pendidikan kesehatan tidak saja diperlukan pada saat wanita hamil, namun diperlukan pendidikan kesehatan lebih awal sebelum wanita tersebut hamil, yaitu pada masa remaja.

Berdasarkan hasil survey, pengetahuan remaja putri mengenai anemia dan pencegahannya di wilayah Kecamatan Jatinangor kurang, sehingga diperlukan pengabdian masyarakat dengan metode pendidikan kesehatan.

Pengetahuan remaja mengenai anemia dan pencegahannya masih kurang. Apabila pengetahuan masih kurang, maka dampaknya adalah kejadian anemia di masyarakat masih cukup banyak. Keadaan anemia pada masa remaja mengakibatkan berbagai masalah seperti konsentrasi belajar menurun, keadaan lemah, letih lesu yang mengganggu aktivitas remaja, serta berakibat jangka panjang yaitu berpengaruh pada kesehatan remaja tersebut saat hamil nanti.

Pengetahuan remaja yang masih kurang, salah satunya disebabkan karena remaja tidak pernah terpapar pendidikan kesehatan mengenai anemia dan pencegahannya. Dalam rangka pengabdian masyarakat untuk mewujudkan generasi remaja yang sehat dan terbebas dari anemia, dibuatlah kegiatan pendidikan kesehatan mengenai anemia dan pencegahannya, selain itu remaja juga diberikan sebuah buku saku mengenai anemia dan pencegahannya.

\section{METODE}

Tahap awal kegiatan ini adalah melakukan survey melalui kuesioner mengenai anemia dan pencegahannya. Metode penelitian secara kuatitatif secara potong lintang. Untuk meningkatkan pengetahuan remaja dilakukan pengabdian masyarakat dengan metode pendidikan kesehatan yang diberikan pada remaja di wilayah kerja Puskesmas Jatinangor. Remaja diberikan pendidikan kesehatan baik. Kegiatan dilakukan di kantor-kantor desa wilayah kerja Puskesmas Jatinangor, dengan tahapan:

1. Survey pengetahuan mengenai anemia dan pencegahannya

2. Pemeriksaan darah lengkap termasuk pemeriksaan kadar hemoglobin

3. Pendidikan kesehatan dan pembagian buku saku

Keberlanjutan dari kegiatan ini adalah setiap tahun akan diadakan pengabdian masyarakat untuk melakukan evaluasi pengetahuan dan masalah anemia remaja. Kegiatan dilakukan oleh mahasiswa Program Studi D4 Kebidanan Fakultas Kedokteran UNPAD.

\section{HASIL DAN PEMBAHASAN}

Dari hasil kuisioner diketahui bahwa pengetahuan remaja mengenai anemia dan pencegahannya adalah 48 orang memiliki pengetahuan kurang, 19 orang memiliki pengetahuan cukup, dan hanya 2 orang yang memiliki pengetahuan baik.

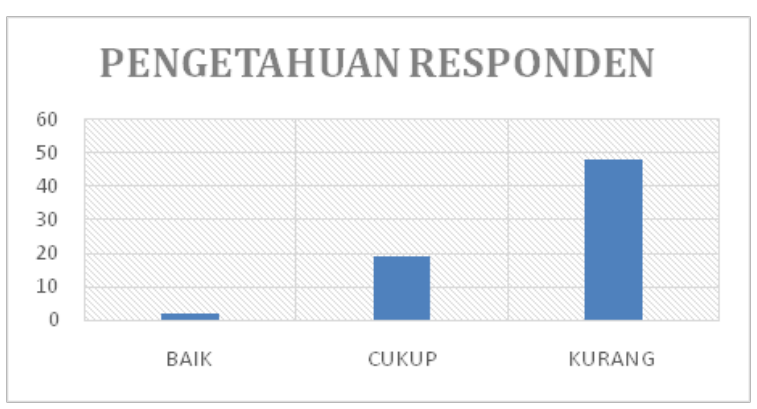

\section{Gambar 1. Pengetahuan Remaja Putri}

Menurut Martini, remaja dengan tingkat pengetahuan yang kurang mempunyai risiko 2,3 kali mengalami anemia dibandingkan dengan remaja yang memiliki pengetahuan yang baik.8 Salah satu upaya untuk meningkatkan pengetahuan seseorang mengenai anemia ialah dengan dilakukannya pendidikan kesehatan. Pendidikan merupakan salah satu faktor yang dapat memengaruhi tingkat pengetahuan seseorang. Pendidikan dapat memengaruhi seseorang termasuk juga perilaku seseorang akan pola hidup.

Berdasarkan hasil penelitian tersebut dilakukan kegiatan pengabdian pada masyarakat melalui pendidikan kesehatan. Pendidikan kesehatan dapat memengaruhi seseorang termasuk juga perilaku seseorang akan pola hidup. Pendidikan kesehatan yang tepat penting dilakukan untuk meningkatkan pengetahuan remaja yang dapat membantu mencegah terjadinya anemia. ${ }^{10}$ Berdasarkan penelitian tersebut menunjukan bahwa terdapat pengaruh yang signifikan dari pendidikan kesehatan terhadap peningkatan pengetahuan.

\section{SIMPULAN}

Simpulan dari penelitian dan pengabdian pada masyarakat ini, yaitu masih terdapat remaja yang memiliki pengetahuan kurang mengenai anemia dan pencegahannya, hal tersebut dapat diatasi salah satunya melalui kegiatan pengabdian pada masyarakat dengan metode pendidikan kesehatan, sehingga dapat mengurangi masalah anemia pada remaja di Indonesia.

\section{UCAPAN TERIMAKASIH}

Penelitian dan Pengabdian Masyarakat ini terlaksana dengan adanya Hibah Riset Fundamental Dosen Unpad. Ucapan terimakasih juga kepada Camat, Kepala Desa, bidan desa, serta kader di wilayah Kecamatan Jatinangor.

\section{DAFTAR PUSTAKA}

World Health Organization. World Health Organization, Adolescent health and development. SEARO. 2017. http://www.searo.who.int/entity/child_ adolescent/topics/adolescent_health/en/. Accessed October 26, 2018. 
RISKESDAS. Penyakit yang ditularkan melalui udara. Jakarta Badan Penelit dan Pengemb Kesehat Dep Kesehat Republik Indones. 2013;(Penyakit Menular):103. doi:10.1007/s13398-014-0173-7.2

Kaur M, Singh A, Bassi R, Kaur H. Nutritional status and anaemia in medical students of SGRDIMSAR, Amritsar. Natl J Physiol Pharm Pharmacol. 2015;5(1):35-49. doi:10.5455/ njppp.2015.5.180720141

TejiK,DessieY,Assebe T,AbdoM.Anaemiaand nutritional status of adolescent girls in Babile District, Eastern Ethiopia. Pan Afr Med J. 2016;24:1-10. doi:10.11604/pamj.2016.24.62.6949

Srivastava A, Kumar R, Sharma M. Nutritional anaemia in adolescent girls: an epidemiological study. Int $J$ Community Med Public Heal. 2016;3(4):808-812. doi:10.18203/2394-6040.ijcmph20160687

Teji K, Dessie Y, Assebe T, Abdo M. Anaemia and nutritional status of adolescent girls in Babile District, Eastern Ethiopia. Pan Afr Med J. 2016;24:62. doi:10.11604/pamj.2016.24.62.6949
Filippi V, Chou D, Ronsmans C, Graham W, Say L. Levels and Causes of Maternal Mortality and Morbidity. The International Bank for Reconstruction and Development / The World Bank; 2016. doi:10.1596/978-1-4648-0348-2_CH3

García-Casal MN, Landaeta-Jiménez M, Puche R, et al. A program of nutritional education in schools reduced the prevalence of iron deficiency in students. Anemia. 2011. doi:10.1155/2011/284050

Verma a, Rawal VS, Kedia G, Kumar D, Chauhan J. Factor Influencing Anaemia Among Girls of School Going Age (6-18 Years) from The Slums of Ahmedabad City. 2004;XXIX(1):25-26.

Joseph MJ, Vardhini D, Nurse S, Hospital AG. International Journal Of Scientific Research Effectiveness Of Stp On Knowledge And Attitude Regarding Prevention Of Iron Deficiency Anemia Among Adolescent Girls Nursing Dr . Maheswari Jaikumar KEYWORDS : 2017;45(8):45-46. 